\title{
Long-Term Effect of High-Intensity Interval and Concurrent Exercise on Blood Coagulation and Fibrinolysis Parameters in Non-Athlete Healthy Young Men
}

\author{
Sobhani V. ${ }^{1}$ PhD, Mohammadi M.T. ${ }^{2}$ PhD, Shirvani H. ${ }^{1}$ PhD, Amini A.* PhD
}

*Exercise Physiology Research Center, Baqiyatallah University of Medical Sciences, Tehran, Iran

1Exercise Physiology Research Center, Baqiyatallah University of Medical Sciences, Tehran, Iran

2Physiology \& Biophysics Department, Medicine Faculty, Baqiyatallah University of Medical Sciences, Tehran, Iran

\begin{abstract}
Aims: Following the sport activities, the blood homeostasis system, being affected by fibrinolysis and coagulation factors, is changed. The aim of this study was to investigate the effects of high-intensity interval and concurrent (aerobic-resistance) long-term sport courses on the blood fibrinolysis and coagulation parameters in healthy non-athlete young persons.

Materials \& Methods: In the semi-experimental study, 30 healthy non-athlete young men were studied in Saqez in 2014. The subjects, selected via simple available sampling method, were randomly divided into three groups including concurrent (aerobic-resistance) trainings, high-intensity interval trainings, and control groups. 8-week trainings (3 times a week) were conducted in both concurrent and high-intensity interval groups. Blood sampling was done before the first session and 30 minutes after the last training session. Data was analyzed by SPSS 19 software using dependent T, one-way ANOVA, and Tukey's post-hoc tests.

Findings: After the training intervention, the number of platelits and the fibrinogen level significantly decreased in concurrent group. In addition, prothrombin time in high-intensity interval group and the D-dimer level in both training groups significantly increased $(\mathrm{p}<0.05)$. The $\mathrm{D}$-dimer concentrations in control and high-intensity interval groups were significantly different. In addition, the number of platelets in concurrent group was significantly different from both control and high-intensity interval groups $(\mathrm{p}<0.05)$.

Conclusion: 8-week high-intensity interval and concurrent trainings reduce the promoter coagulation activity in the helthy non-athlete young men, while increase the fibrinolytic activity.
\end{abstract}

\section{Keywords}

Circuit-Based Exercise [https://www.ncbi.nlm.nih.gov/mesh/68065327];

Blood Coagulation [https://www.ncbi.nlm.nih.gov/mesh/68001777];

Fibrinolysis [https://www.ncbi.nlm.nih.gov/mesh/68005342]

\footnotetext{
*Corresponding Author Tel: +98 (87) 36226055 Fax: +98 (21) 88600030

Address: Exercise Physiology Research Center, Baqiyatallah University of Medical Sciences, Shahid Nosrati Alley, South Sheikh Bahaei Avenue, Mollasadra Street, Tehran, Iran. Post Box: 19395-5487 amir.amini466@gmail.com Received: January 8, 2015 
مقدمه

بيمارىهاى ايسكمى قلب و عروق از مهمترين دلايل مركَومير در

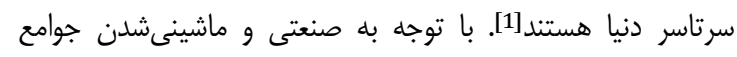
امروزى و افزايش كمتحركى در ميان افراد جامعه بلهويزه كارمندان

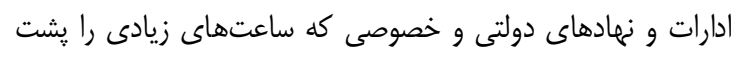

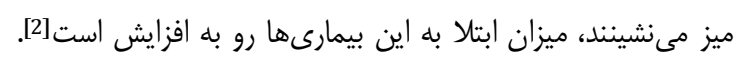

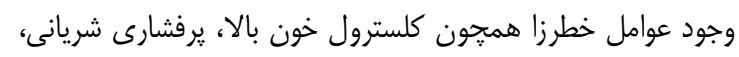

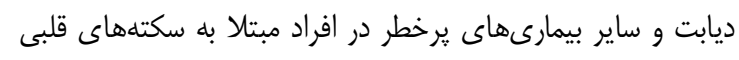

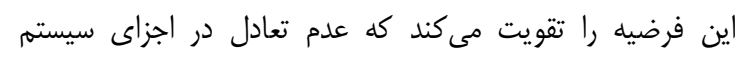

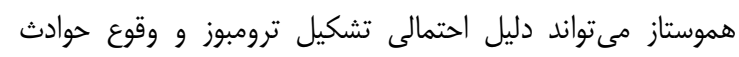

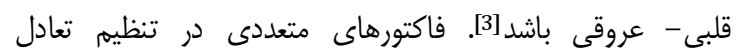
هموستاز خون نقش دارند كه بعضى از آنها موسوم به سيه سيستم

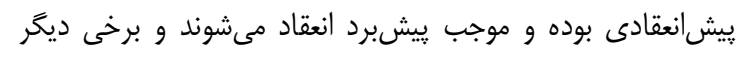

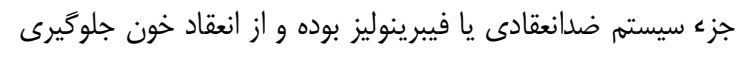

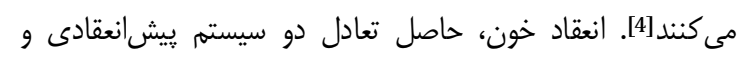
ضدانعقادى است. بر پايه نتايج مطالعات، سيسته هموستاز خون كه تحت تاثير

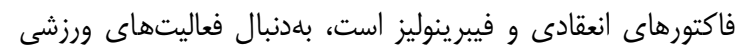

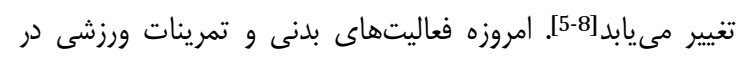

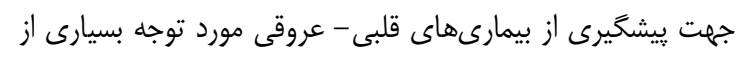

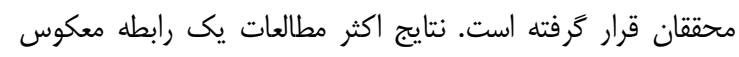

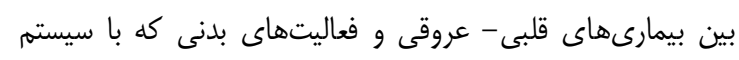

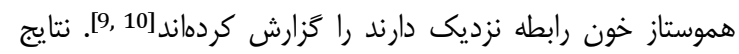

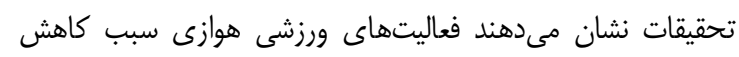

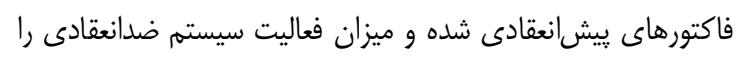

$$
\text { افزايش مى دهند. }
$$

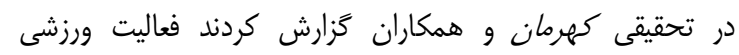

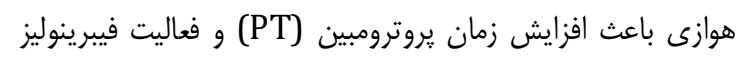

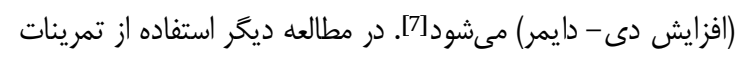

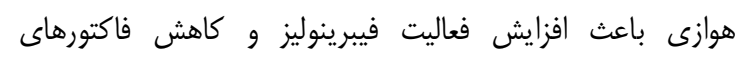

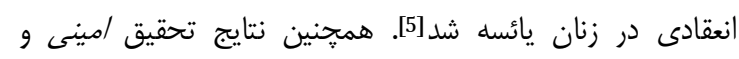

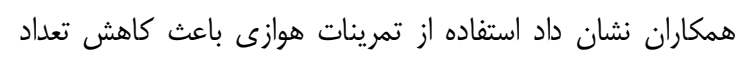

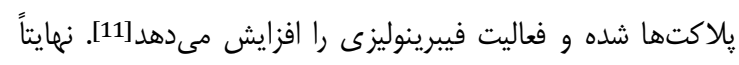

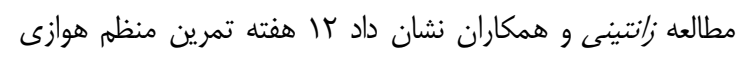
سبب كاهش غلظت فيبرينوزن خون

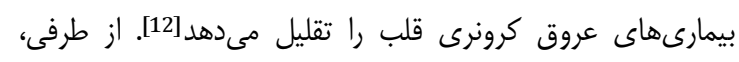

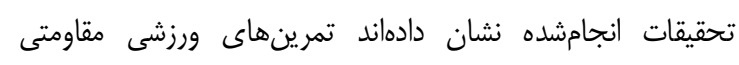

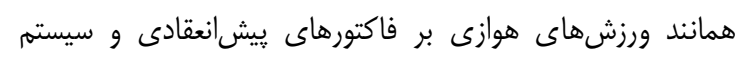

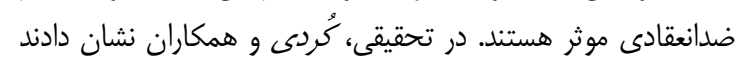

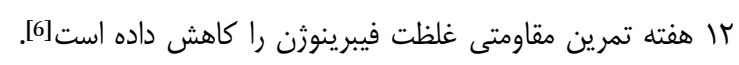

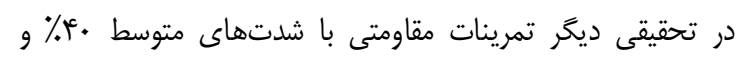

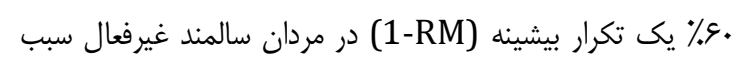

تاثير طولانىمدت تمرينات تناوبى با شدان

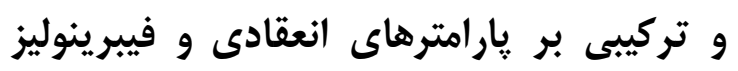
خون در مردان جوان سالم غيرورزشكار

وحيد سبحانى PhD

مركز تحقيقات فيزيولوثى ورزش، دانشكاه علوم بزشكى بقيها... (عج)، تهران، ايران

محمدتقى محمدى PhD

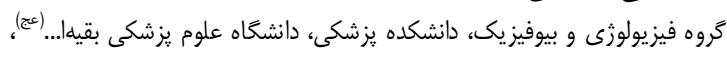
تهران، ايران

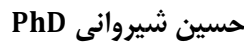

مركز تحقيقات فيزيولوزى ورزش، دانشكاه علوم يزشكى بقيها...(ج)، تهران، ايران

PhD " امير امينى تمقيقت فيز

مركز تحقيقات فيزيولوزى ورزش، دانشعاه علوم يزشكى بقيها...(عج)، تهران، ايران

קكيده

اهداف: براساس نتايج برخى مطالعات، سيستم هموستاز خون كه تحت

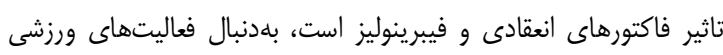

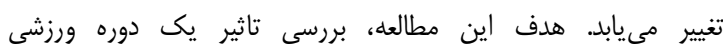

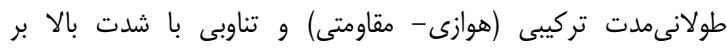

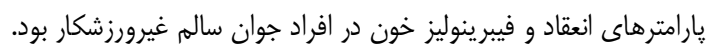

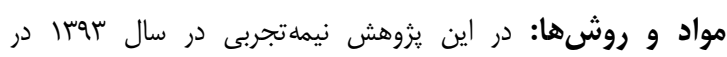

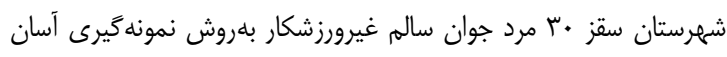

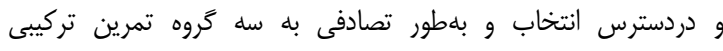

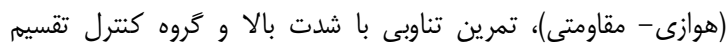

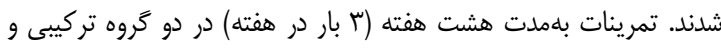

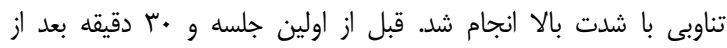

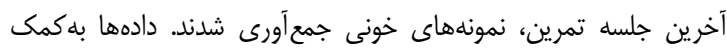

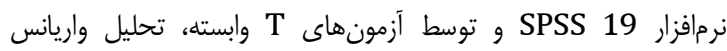
يكىطرفه و آزمون تعقيبى توكى مورد تحليل قرار كرفتند.

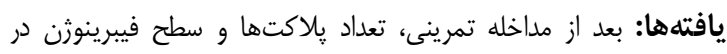

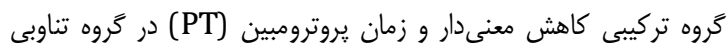

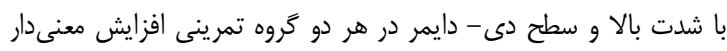

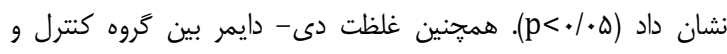

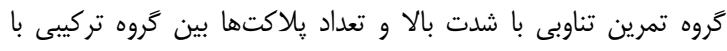

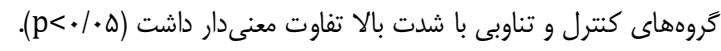

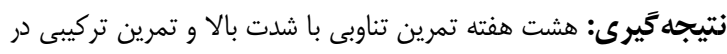

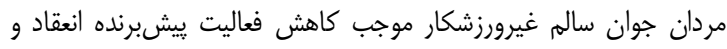

افزايش فعاليت فيبرينوليزى مى شعودان كليدوازهها: تمرين تناوبى با شدت بالا، تمرين تركيبى، انعقاد خون، فيبرينوليز

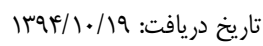

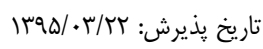
"نويسنده مسئول: amir.amini466@gmail.com 
تاثير طولانى مدت تمرينات تناوبى با شدت بالاو تركيبى بر هارامترهاى انعقادى و فيبر ينوليز خون در مردان جوان سالم غيرورزشكار المبار

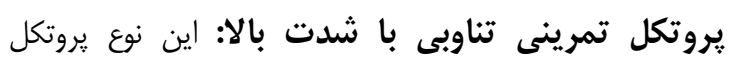

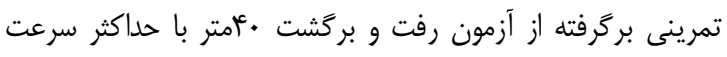

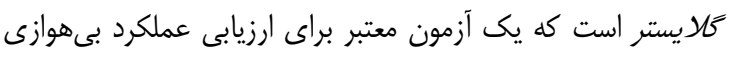

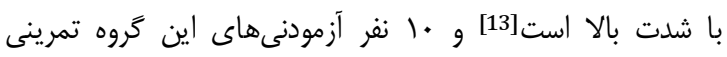

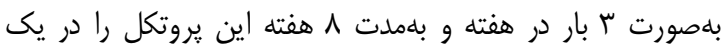

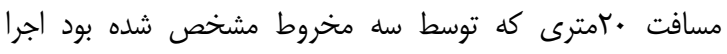

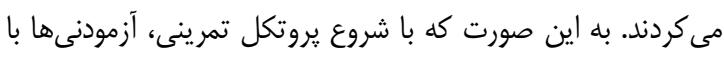

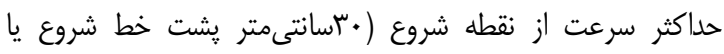

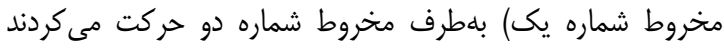

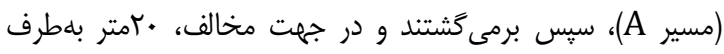

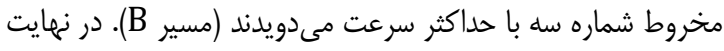

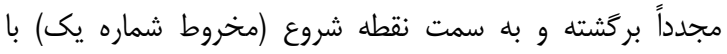

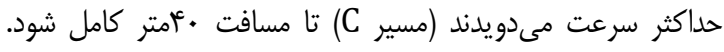

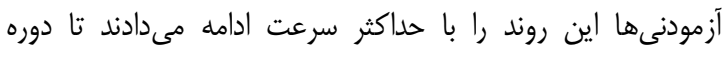

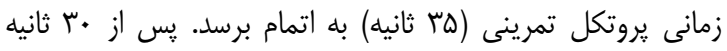

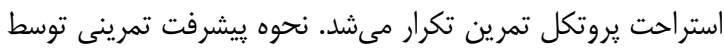

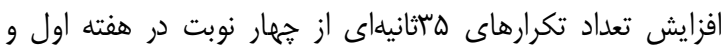

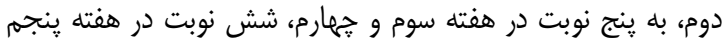

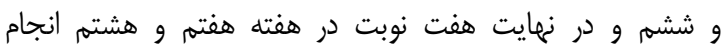
مىشد. قبل از شروع يروتكل تمرينى در هر جرئ نلسه، آزمودنىها

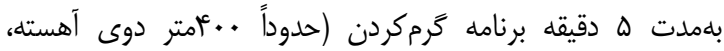

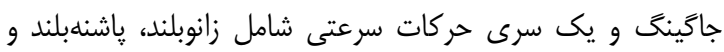

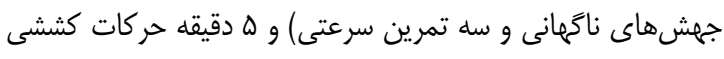

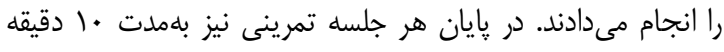

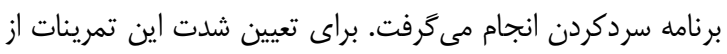

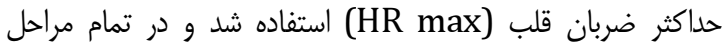

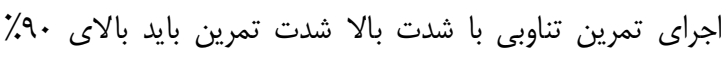

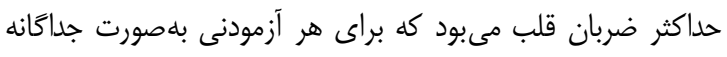

محاسبه شد.

يروتكل تمرينى تركيبى: آزمودنىهاى كروه تمرين تركيبى

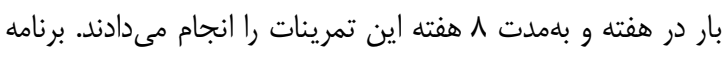

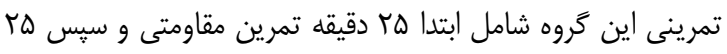

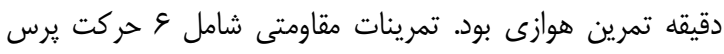

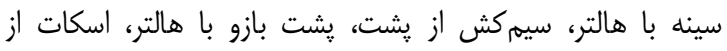

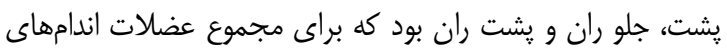

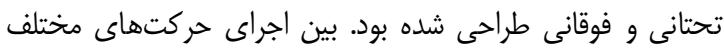

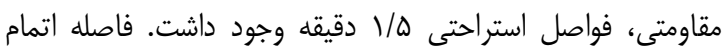

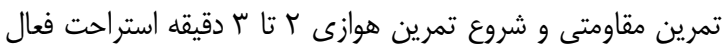

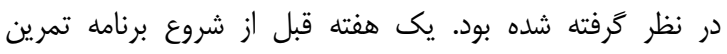

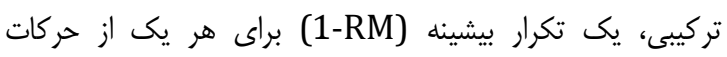

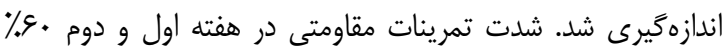

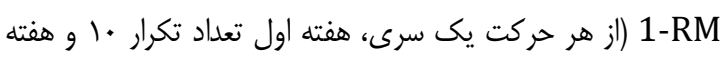

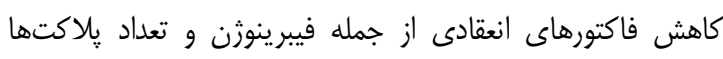

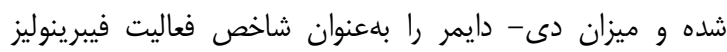
افزايش داد[8].

نتايج ارايهشده بالا بهخوبى تاثير تمرينات هوازى و مقاومتى بر بران

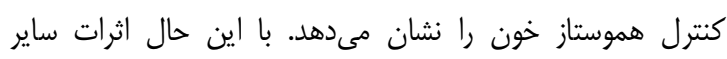

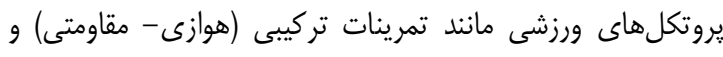

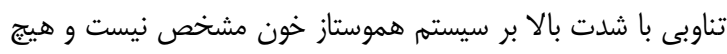
مطالعالى تاكنون در اين زمينه صورت نكخرفته است.

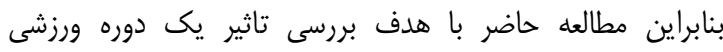

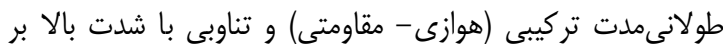

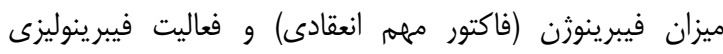

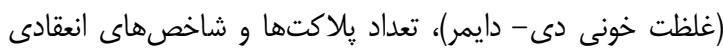

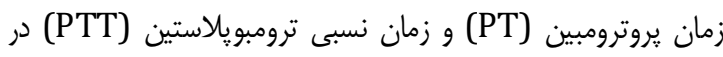
افراد جوان سالم غيرورزشكار انجام شد.

\section{مواد و روشها}

اين يُوهش نيمهتجربى در تابستان سال سوسا در شهرستان سقان

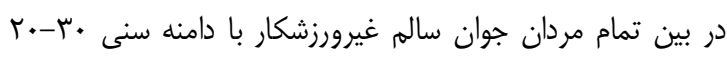

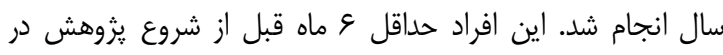

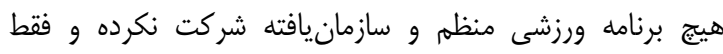

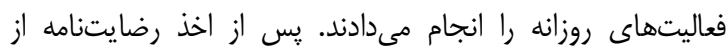

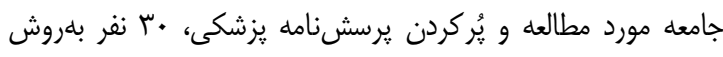

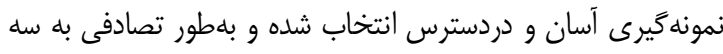

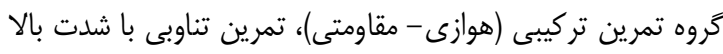
و كروه كنترل تقسيم شدند.

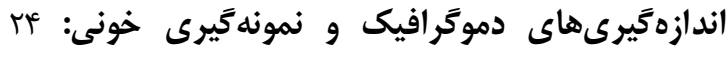

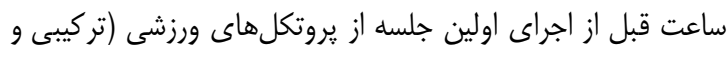

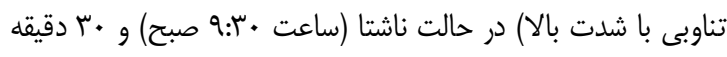

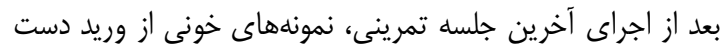

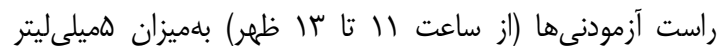

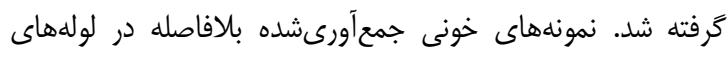
حاوى ماده ضدانعقاد EDTA (اتيلن دى آمين تترا استيكاسيد)

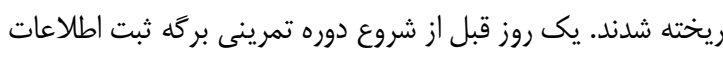

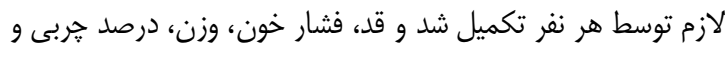

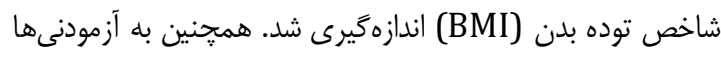

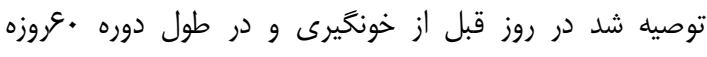

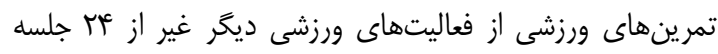

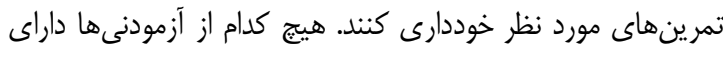

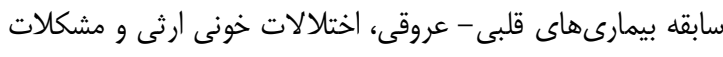

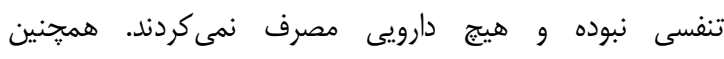

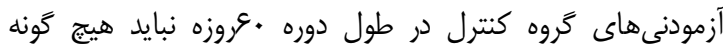
فعاليت ورزشى را انجام مى دادند. 
جدول () مقايسه ميانكَين آمارى شاخصهاى دموكرافيك كَروهاى تجربى و

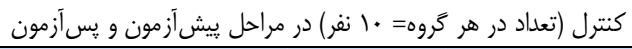

\begin{tabular}{|c|c|c|}
\hline معنىدارى سطح & مر شِآزمون & يِشرآزمون \\
\hline $\begin{array}{l}\cdot \mid \cdot \cdot 1 \\
\cdot / \cdot 11 \\
. / 191\end{array}$ & $\begin{array}{l}\mid V / \cdots \pm T / 1 . \\
\mid \varepsilon / T \cdot \pm T / r . \\
\mid \varepsilon / \Lambda \cdot \pm 1 / r .\end{array}$ & 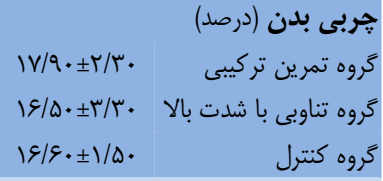 \\
\hline $\begin{array}{l}. / \cdot 4 F \\
.1 \cdot 11 \\
. / 19 \Lambda\end{array}$ & $\begin{array}{l}V N / r \cdot \pm I I / \Delta \cdot \\
V / / \Delta \cdot \pm I r / l . \\
V \Psi / \varepsilon \cdot \pm \Delta / \Delta .\end{array}$ & 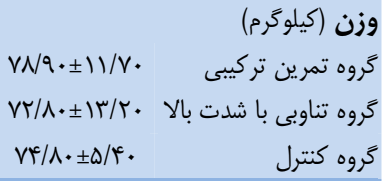 \\
\hline 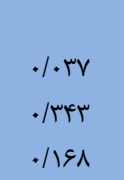 & $\begin{array}{l}r E / \cdot \cdot \pm T / V F \\
r T / \Lambda \cdot \pm T / T . \\
r F / \cdot \cdot \pm 1 / \Lambda .\end{array}$ & 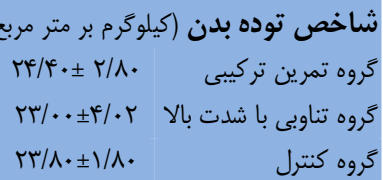 \\
\hline
\end{tabular}

همجنين مقدار PT در گروه تمرين تناوبى با شدت بالا و سطح

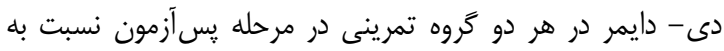

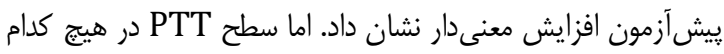

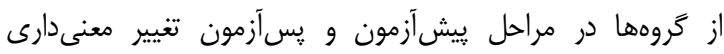

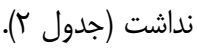

\begin{tabular}{|c|c|c|c|}
\hline معنىدارى سطح & مر هـ آزمون & بيش مرحله & شاخص \\
\hline $\begin{array}{l}.1 \cdot .1 \\
.1 .94 \\
. / 4 \cdot 1\end{array}$ & 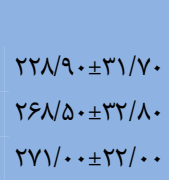 & 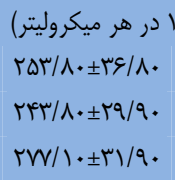 & 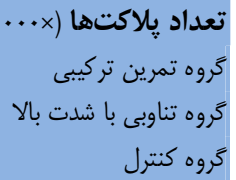 \\
\hline $\begin{array}{l}. / 148 \\
.1 . .9 \\
. / 494\end{array}$ & $\begin{array}{l}\left|r / Q \varepsilon_{ \pm} \cdot / q\right| \\
\mid r / \Delta T \pm \cdot / T^{\prime} \\
\mid r / T \cdot \pm \cdot / \Delta T\end{array}$ & 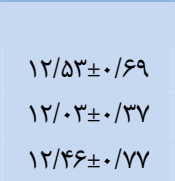 & 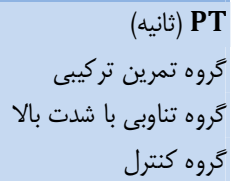 \\
\hline $\begin{array}{l}\cdot / 1 \cdot{ }^{4} \\
. / 981 \\
. / 1 \vee 9\end{array}$ & 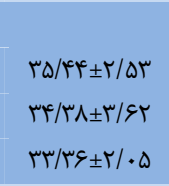 & 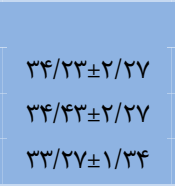 & 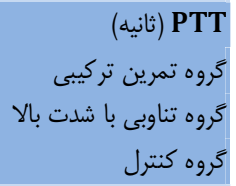 \\
\hline $\begin{array}{l}. / \cdots 1 \\
. / 1 Y \mid \\
. / 1 F F\end{array}$ & 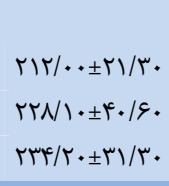 & 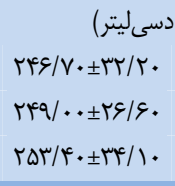 & 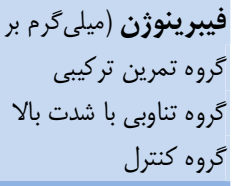 \\
\hline $\begin{array}{l}. / \cdots 1 \\
. / \cdots r \\
. / 11 .\end{array}$ & $\begin{array}{l}1 \xi \Delta / q \cdot \pm \Delta \cdot / \kappa \cdot \\
r \cdot q / r \cdot \pm \varepsilon \cdot / \cdot \cdot \\
\mid r \Delta / r \cdot \pm r r / q .\end{array}$ & 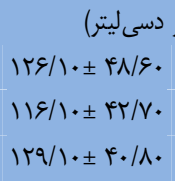 & 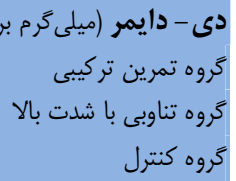 \\
\hline
\end{tabular}

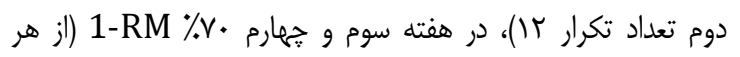

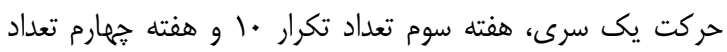

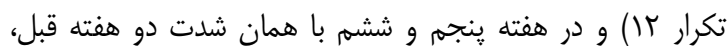

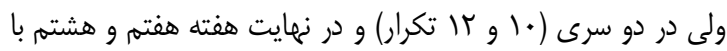

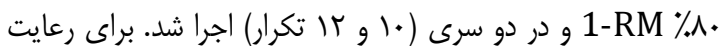

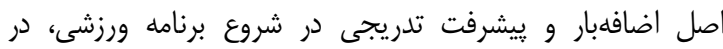

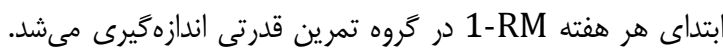

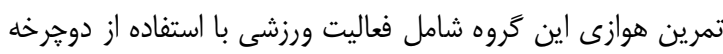
ثابت بود. مدتزمان هر جلسه حدوداً

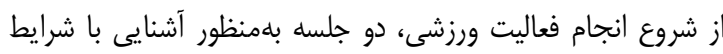

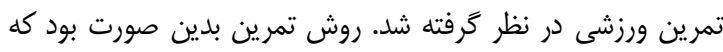

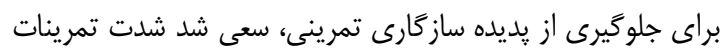

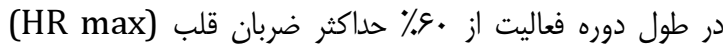

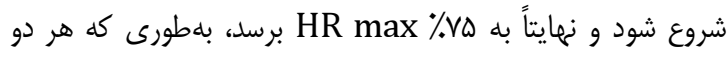

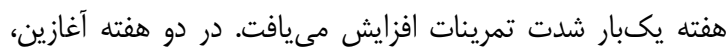

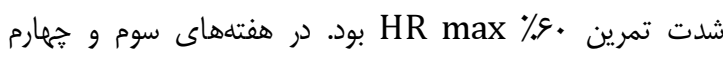

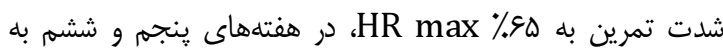

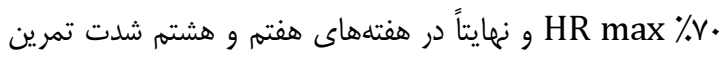

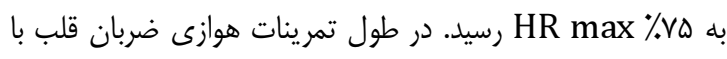
استفاده از ضربانسنج دستخاه دوخرخه كارسنج كنترل مى فيد.

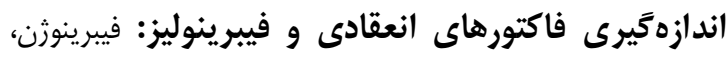
PTT با روش انعقادى و توسط دستخاه (استاكو؛ آلمان) و

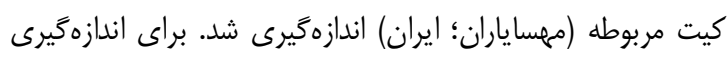

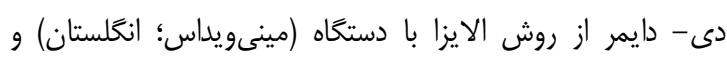

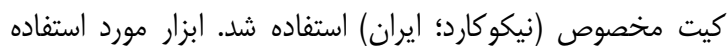

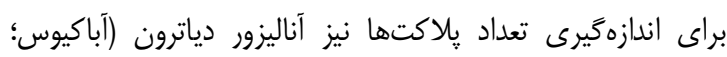
آلمان) و كيت مخصوص (مهساياران؛ ايران) بود.

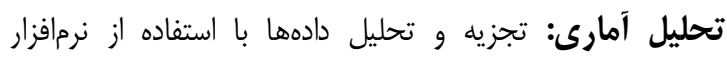
SPS 19

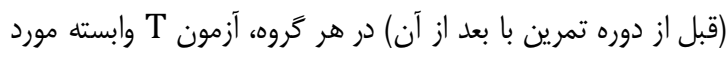

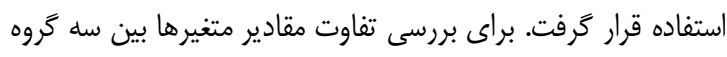

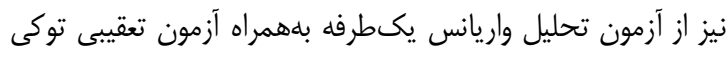

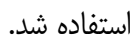

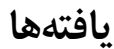

متغيرهاى دموكرافيك وزن، درصد حربى و شاخص توده بدن در

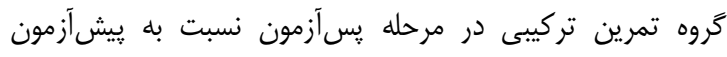

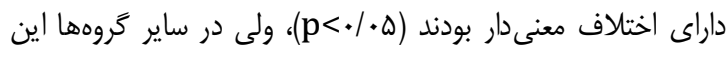

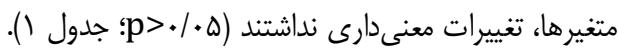

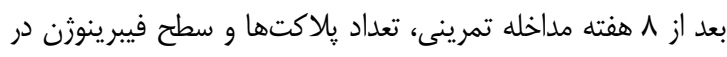

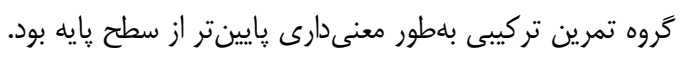




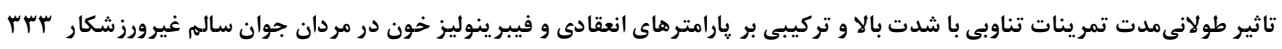

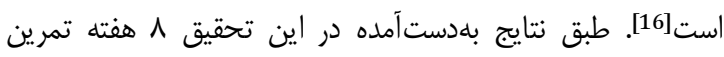

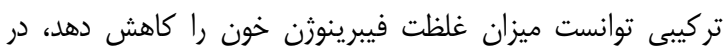

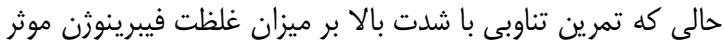

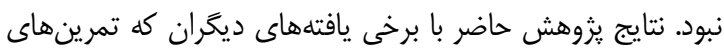

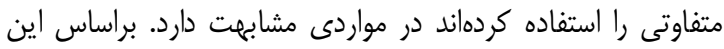
مطالعات تمرين هوازى و مقاومتى سبب كاهش ميزان فيبرينوثن خون مىشود[5, 8, 11, 17. محققان مذكور دليل كاهش فيبرينوثن

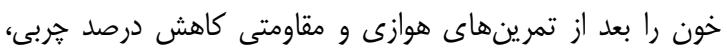
وزن آزمودنىها و شاخص توده بدن عنوان كردهاند كه ارتباط مستقيمى با غلظت فيبرينوزن خون دارد. با توجه به اينكه در مطالعه حاضر بعد از دوره تمرين تركيبى هر سه متغير مذكور در آزمودنىها

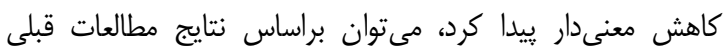
نتيجه خون احتمالاً كاهش سه متغير فوق بوده است.

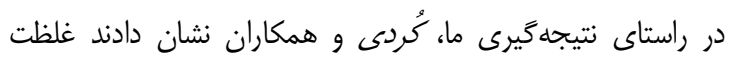

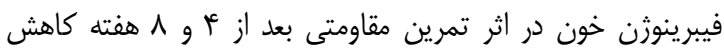

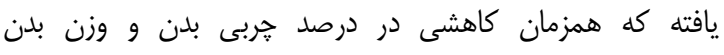

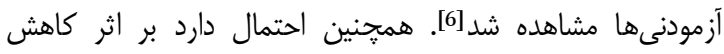

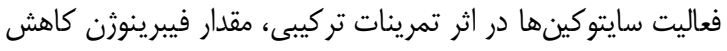

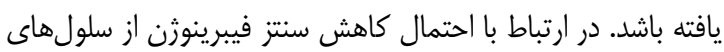
كبدى مىتوان به سازگًارى حاصل در سيستم عضلانى و اسكلتى

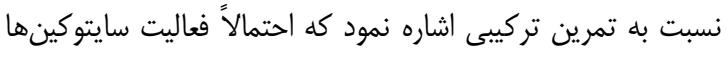

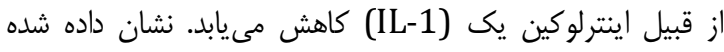

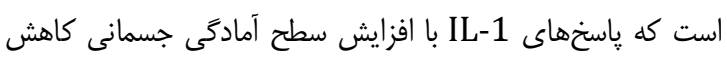
يافته است[18]، لذا اين احتمال وجود دارد كه يس إس از تمرينات تركيبى بلمدات 1 هفته فعاليت سايتوكينها از قبيل IL-1 كاهش إنش يابد كه اين كاهش بلنوبه خود مىتواند در كاهش فيبرينوزن حاصل از سنتز كبدى نيز تاثير كذار باشد.

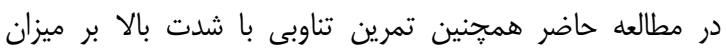

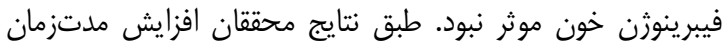

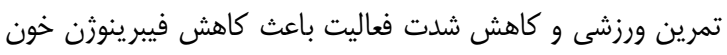

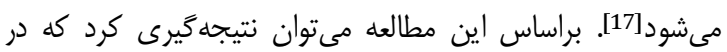

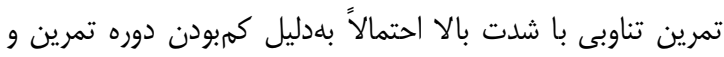

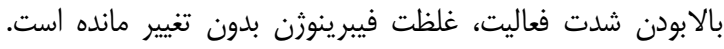

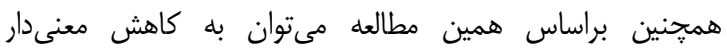

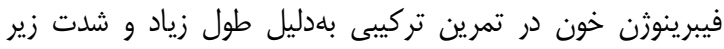

بيشينه فعاليت ورزشى در هر جلسه تمرين تركيبى تاكيد نمود. بر קايه نتايج مطالعات ييشين فعاليت فيبرينوليزى (دى - دايمر)

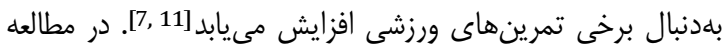
حاضر استفاده از ^ هفته تمرين ورزشى تركيبى و تناوبى با شدئ ورست

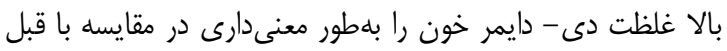

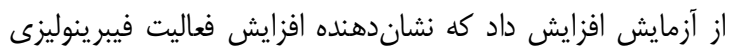

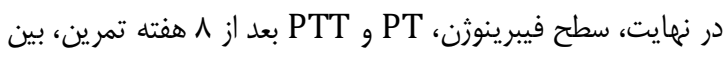

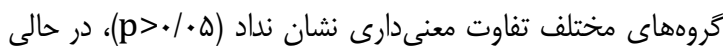

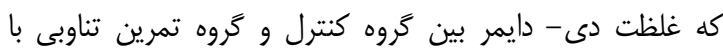

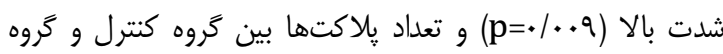

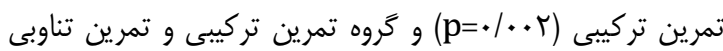

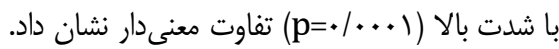

\section{بحث}

نتايج مطالعه حاضر نشان داد ^ هفته تمرين تناوبى با شدت بالا، زمان يروترومبين (PT) و شاخص فيبرينوليز (دى - دايمر) را بهطور

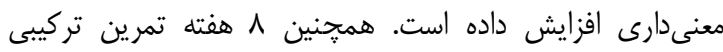

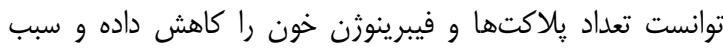

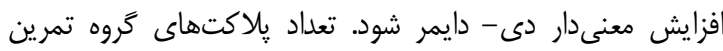

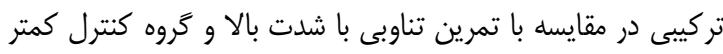

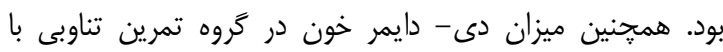
شدت بالا نسبت به گروه كنترل بيشتر بود. نتايج مطالعات قبلى در زمينه تاثير تمرينات ورزشى بر سيسته هموستاز متناقض است[5] تفاوت در يروتكلهاى تمرينى، شدت تمرينات، سن، جنس، سطح

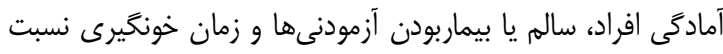
داد. از طرفى بيشتر يروهشها تاثير تمرينات هوازى و مقاومتى را

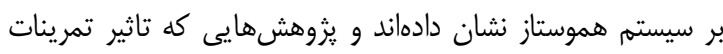

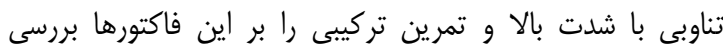

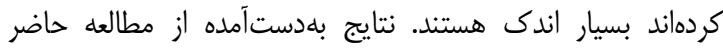
نشاندهنده تغييرات برخى شاخصهاى انعقاد خون يس از 1 هفته تمرين تناوبى با شدت بالا و تمرين تركيبى بود. فعاليت بدنى و ورزش هاى مختلف نقش مهرى راو را در كنترل خودكار

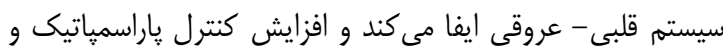
كاهش كنترل سمياتيك قلب در اثر فعاليت بدنى كزارش شئ شده است[11]. ورزش هاى مقاومتى و تناوبى با شدت بالا موجب فعاليت

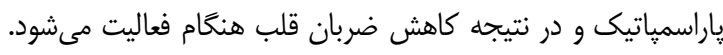
نشان داده شده است كه فعاليتهاى ورزشى هوازى موجب كاهش

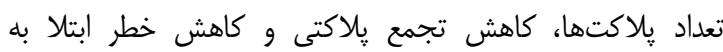
بيمارىهاى قلبى - عروقى مىشود [14]. از ميان شاخصهاى انعقادى، فيبرينوزن (فاكتور انعقادى شماره يك) يكى از بهترين شاخصها در ارزيابى احتمالى بيمارىهاى قلبى - عروقى است[15]. فيبرينوزن سوبستراى نهايى سيسته سيتم انعقاد بوده و توسط ترومبين به فيبرين تبديل مىشود. بنابراين مىتوان

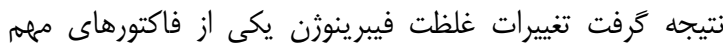
موثر بر انعقاد خون است. نتايج مطالعات نشاندهنده تغييرات غلظت

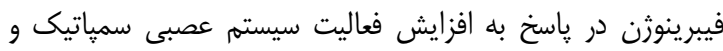

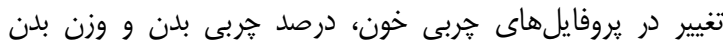


شدت بالا، جون pH خون و اسيدلاكتيك افزايش مىيابد، بنابراين

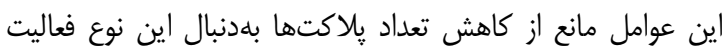

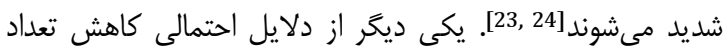

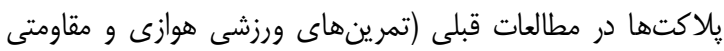

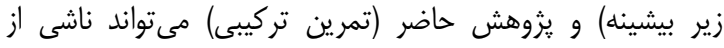

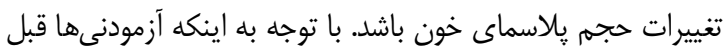

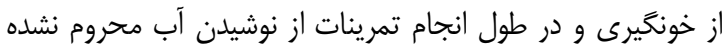

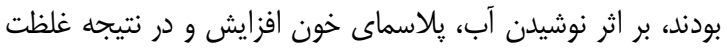

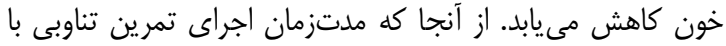

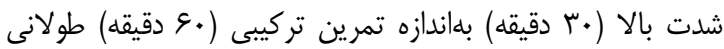

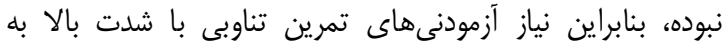

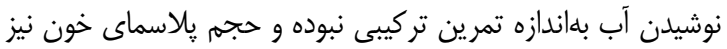
افزايش زيادى نداشته است.

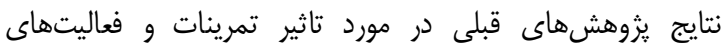

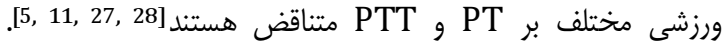
تعدادى از مطالعات بيانكر طولانىشدن زمانهاى بانى انعقادى مسير

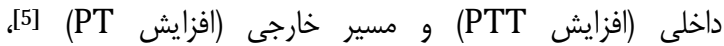
عدمتغيير[28] و كوتاهشدن اين شاخصها (كاهش PT و PTT) هستند[11, 27]. طبق نتايج بهدستآمده در اين تحقيق 1 هفته

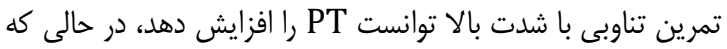

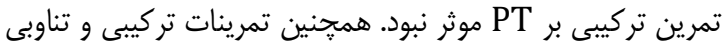

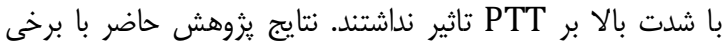

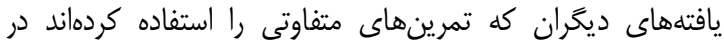

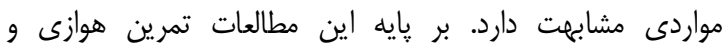

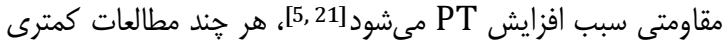
روى تغييرات PT بهدنبال فعاليت ورزشى به نسبت PTT انجام

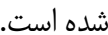
شاخص PT براى بررسى كارآيى مسير خارجى و معمول انعقاد

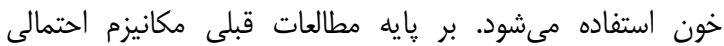

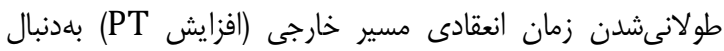

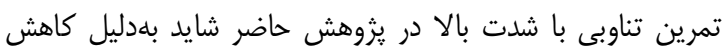

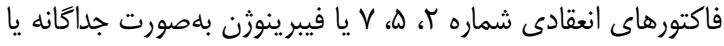

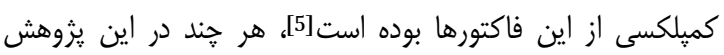

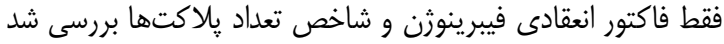

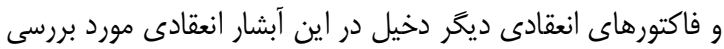

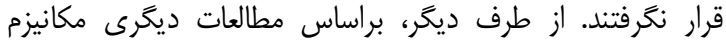

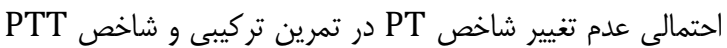

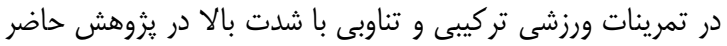

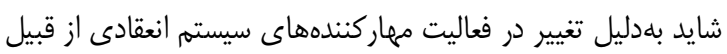

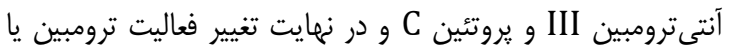

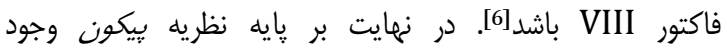

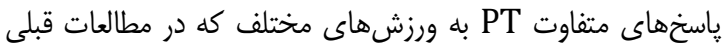

در يايان 1 هفته براى هر دو نوع يروتانكل وران ورزشى بود. در راستاى

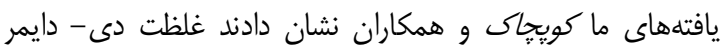

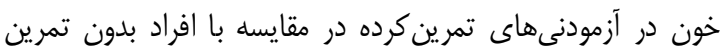
بيشتر است[19]. همجنين در مواردى تغييرات فعاليت فيبرينوليزى

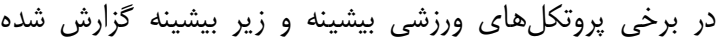

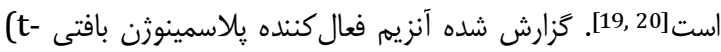
كه توسط سلولهاى اندوتليال عروقى توليد شده و

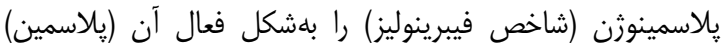

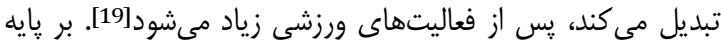

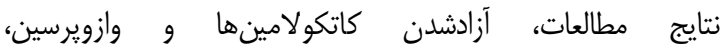
هييوكلايسمى، افزايش ترومبين خون و آسيب به ديواره عروق كه الهين در طول فعاليت ورزشى اتفاق مىافتد، باعث افزايش رهايى آنزيم

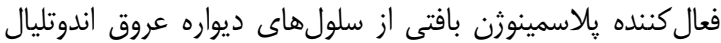

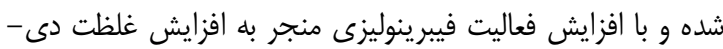

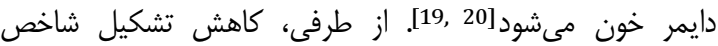

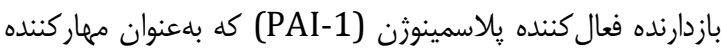

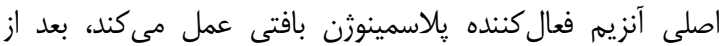

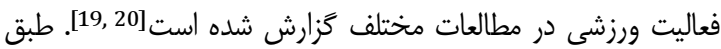
مكانيزمهاى ارايهشده بهنظر مىرسد در مطالعه حاضر بهكاركيرى

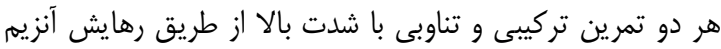

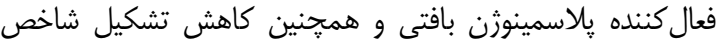

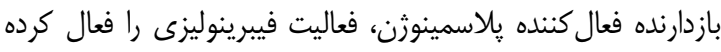
و منجر به افزايش غلظت دى - دايمر شده است. بر پايه نتايج مطالعات قبلى، از عوامل تاثيركذار بر تغييرات تعدات

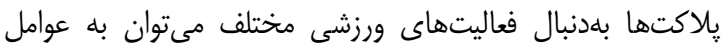

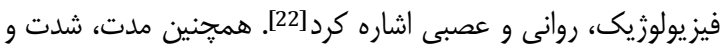

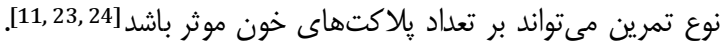

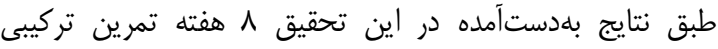

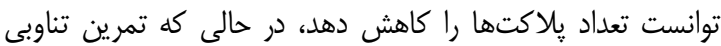

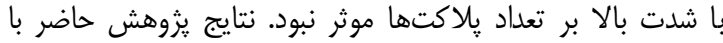
برخى يافتههاى ديخران كه تمرينهاى متفاوتى را استفاده كردهاند براند

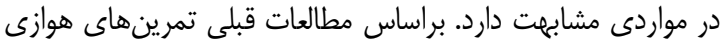

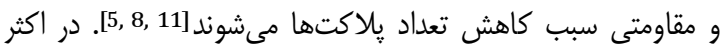

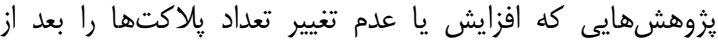

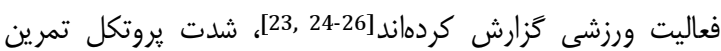

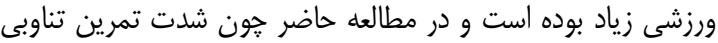

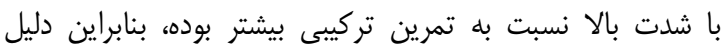

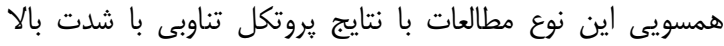

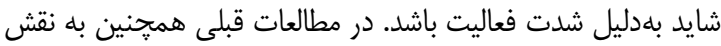
برخى عوامل مانند تغييرات pH و اسيدلاكتيك خون كه مانع تغيير غلظت קِلاكتها بهدنبال فعاليت ورزشى شديد مى شوند اشاره شده

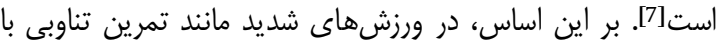




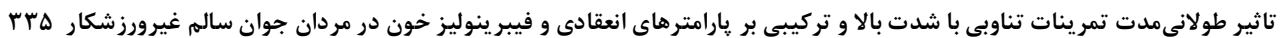

Council on Nutrition, Physical Activity, and Metabolism (Physical Activity Committee) in collaboration with the councils on Cardiovascular Disease in the Young and Cardiovascular Nursing. Circ. 2006;114(11):1214-24.

3- Pollock ML, Franklin BA, Balady GJ, Chaitman BL, Fleg JL, Fletcher B, et al. Resistance exercise in individuals with and without cardiovascular disease benefits, rationale, safety, and prescription an advisory from the committee on exercise, rehabilitation, and prevention, council on clinical cardiology, American Heart Association. Circ. 2000;101(7):828-33.

4- Bakhtiari K, Meijers JC, de Jonge E, Levi M. Prospective validation of the International Society of Thrombosis and Haemostasis scoring system for disseminated intravascular coagulation. Crit Care Med. 2004;32(12):2416-21.

5- Jahangard T, Torkaman G, Ghoosheh B, Hedayati M, Dibaj A. The effect of short-term aerobic training on coagulation and fibrinolytic factors in sedentary healthy postmenopausal women. Matur. 2009;64(4):223-7.

6- Kordi MR, Ahmadizad S, Nikokheslat S. The effect of 12 weeks resistance training on the levels of rest hemorheology variables young men. Sports Res Sci. 2010;27(5):105-22. [Persian]

7- Kahraman S, Demirkan F, Bediz C, Alacacioglu I, Aksu I. The effect of exercise on fibrinolytic and coagulation systems in healthy volunteers. J Thromb Haemost. 2007;5(Suppl 2):P-S-362.

8- Amini A, Kordi MR, Gaini AA, Ahmadi A, Veysi K. Effect of resistance exercise on coagulation and fibrinolytic factors in inactive aged men. Horizon Med Sci. 2012;18(3):103-8. [Persian]

9- Van den Burg P, Hospers JE, Mosterd WL, Bouma BN, Huisveld IA. Aging, physical conditioning, and exerciseinduced changes in hemostatic factors and reaction products. J Appl Physiol. 2000;88(5):1558-64.

10- Bobeuf F, Labonté M, Khalil A, Dionne IJ. Effect of resistance training on hematological blood markers in older men and women: A pilot study. Curr Gerontol Geriat Res. 2009;2009:1-4.

11- Amini A, Kordi MR, Gaini AA, Ahmadi A, Ayoubian H, Lahoorpour $F$. The effects of aerobic exercises on coagulation and fibrinolytic factors in inactive aged men. J Kurdistan Univ Med Sci. 2011;15(4):25-32. [Persian] 12- Zanettini R, Bettega D, Agostoni O, Ballestra B, del Rosso G, di Michele R, et al. Exercise training in mild hypertension: effects on blood pressure, left ventricular mass and coagulation factor VII and fibrinogen. Cardiol. 1997;88(5):468-73.

13- Glaister M, Hauck H, Abraham CS, Merry KL, Beaver D, Woods B, et al. Familiarization, reliability, and comparability of a 40-m maximal shuttle run test. J Sports Sci Med. 2009;8(1):77-82.

14- Wang JS, Jen CJ, Chen HI. Effects of exercise training and deconditioning on platelet function in men. Arterioscler Thromb Vasc Biol. 1995;15(10):1668-74.

15- Mutanen M, Freese R. Fats, lipids and blood coagulation. Curr Opin Lipidol. 2001;12(1):25-9.

16- Alzahrani SH, Ajjan RA. Coagulation and fibrinolysis in diabetes. Diab Vasc Dis Res. 2010;7(4):260-73.

17- Smith JE, Garbutt G, Lopes P, Pedoe DT. Effects of prolonged strenuous exercise (marathon running) on biochemical and haematological markers used in the investigation of patients in the emergency department. Br J Sports Med. 2004;38(3):292-4.

18- Duncan BB, Schmidt MI, Chambles LE, Folsom AR, Charpenter M, Heiss G. Fibrinogen, other putative

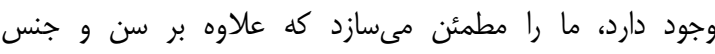

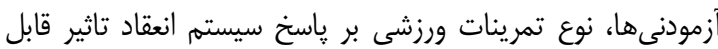

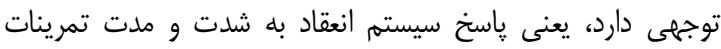

$$
\begin{aligned}
& \text { ورزشى بستخى دارد[29]. } \\
& \text { از جمله محدوديتهاى اين مطالعه، عدم دستهبندى آزمودنىها }
\end{aligned}
$$

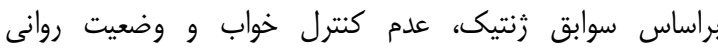

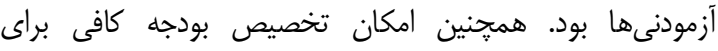

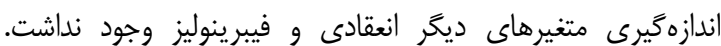

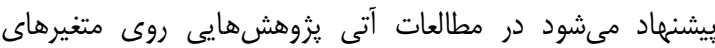

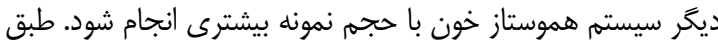

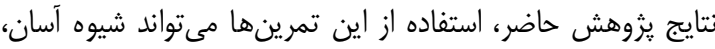

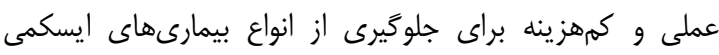

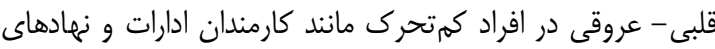

$$
\begin{aligned}
& \text { دولتى و خصوصى باشد كه در حال حاضر درصد بيشتر مرگتوميرها } \\
& \text { را بعد از سرطان در سطح دنيا به خود اختصاص داده است. }
\end{aligned}
$$

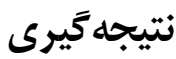

هشت هفته تمرين تناوبى با شدت بالا و تمرين تركيبى در مردان

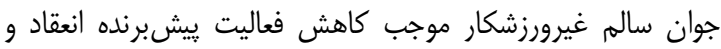

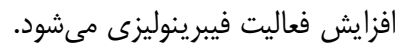

تشكر و قدردانى: با سياس فراوان از آقاى دكتر برويز سليمانى مسئول فنى آزمايشگاه مهر سقز و تمامى افرادى كه دياس در يروهش حاضر مرا يارى كردند. بىترديد بدون همكارى اين عزيزان انجام

$$
\text { يثوهش حاضر ممكن نبود. }
$$

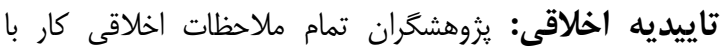
آزمودنىهاى انسانى تاييدشده توسط كميته اخلاق دانشگاه علوم

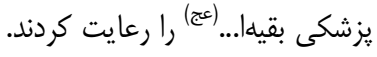
تعارض منافع: هيج زونه تعارض منافعى زَارش نشده است. منابع مالى: اين مطالعه منتج از طرح در قالب رساله دكترى براى دريافت درجه "دكترى تخصصى فيزيولوزى ورزشى"، با مائ حمايت بودجه ارايهشده از مركز تحقيقات فيزيولوزى ورزشى دانشگاه علوم يزشكى بقيه|..(عج) بوده كه در تابستان سوسا و در استان كردستان

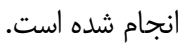

\section{منابع}

1- Fuster V, Stein B, Ambrose J, Badimon L, Badimon J, Chesebro J. Atherosclerotic plaque rupture and thrombosis. Evolving concepts. Circ. 1990;82(3 Suppl):1147-59.

2- Pate RR, Davis MG, Robinson TN, Stone EJ, McKenzie TL, Young JC, et al. Promoting physical activity in children and youth a leadership role for schools: A scientific statement from the American Heart Association 
25- Soleimani M, Amini A, Ahmadi A, Atashak S, Mehdivand A, Kawsari E, et al. Effect of short-term supplementation of cocoa on platelet factors (Plt, MPV, PDW) of athlete male's blood after an exhaustive aerobic exercise. J Kurdistan Uni Med Sci. 2013;18(4):18-27. [Persian]

26- San Jose MCZ, Apaga NEP, Florento L, Gan RN. Effects of aerobic exercise and training on coagulation, platelet aggregation, and plasma lipids. Vasc Dis Prev. 2005;2(2):145-50.

27- Menzel K, Hilberg T. Blood coagulation and fibrinolysis in healthy, untrained subjects: Effects of different exercise intensities controlled by individual anaerobic threshold. Eur J Appl Physiol. 2011;111(2):253-60.

28- Hilberg T, Gläser D, Reckhart C, Prasa D, Stürzebecher J, Gabriel HH. Blood coagulation and fibrinolysis after long-duration treadmill exercise controlled by individual anaerobic threshold. Eur J Appl Physiol. 2003;90(5-6):639-42.

29- Piccone G, Fazio F, Giudice E, Grasso F, Caola G. Exercise-induced change in clotting times and fibrinolytic activity during official 1600 and 2000 meters trot races in standard horses. Acta Vet Brno. 2005;74(4):509-14. markers of inflammation, and weight gain in middleaged adults--the ARTC study: Atherosclerosis risk in communities. Obes Res. 2000;8(4):279-86.

19- Kupchak BR, Volk BM, Kunces LJ, Kraemer WJ, Hoffman MD, Phinney SD, et al. Alterations in coagulatory and fibrinolytic systems following an ultramarathon. Eur J Appl Physiol. 2013;113(11):2705-12.

20- Parker BA, Augeri AL, Capizzi JA, Ballard KD, Kupchak BR, Volek JS, et al. Effect of marathon run and air travel on pre-and post-run soluble d-dimer, microparticle procoagulant activity, and p-selectin levels. Am J Cardiol. 2012;109(10):1521-5.

21- Posthuma JJ, van der Meijden PE, ten Cate H, Spronk HM. Short-and Long-term exercise induced alterations in haemostasis: A review of the literature. Blood Rev. 2015;29(3):171-8.

22- Heber S, Volf I. Effects of physical (in) activity on platelet function. Biomed Res Int. 2015;2015:1-11.

23- Ahmadizad S, El-Sayed MS, MacLaren DP. Responses of platelet activation and function to a single bout of resistance exercise and recovery. Clin Hemorheol Microcirc. 2006;35(1-2):159-68.

24- Ahmadizad S, El-Sayed MS. The effects of graded resistance exercise on platelet aggregation and activation. Med Sci Sports Exerc. 2003;35(6):1026-32. 